\title{
Effects of Imatinib Mesylate in Interstitial Cells of Cajal from Murine Small Intestine
}

\author{
Byung Joo Kim, ${ }^{a}$ Han Chae,,${ }^{a}$ Young Kyu Kwon,,${ }^{a}$ Seok Chol,${ }^{b}$ Jae Yeol Jun,,${ }^{b}$ Ju-Hong Jeon, ${ }^{c}$ \\ Insuk So, ${ }^{*, c}$ and Seon Jeong $\mathrm{KIM}^{*, d}$ \\ ${ }^{a}$ Division of Longevity and Biofunctional Medicine, Pusan National University School of Korean Medicine; Yangsan \\ 626-870, Republic of Korea: ${ }^{b}$ Department of Physiology, Chosun University College of Medicine; Gwangju 501-759, \\ Republic of Korea: ${ }^{c}$ Department of Physiology, Seoul National University College of Medicine; Seoul 110-799, Republic \\ of Korea: and ${ }^{d}$ Center for Bio-Artificial Muscle and Department of Biomedical Engineering, Hanyang University; Seoul \\ 133-791, Republic of Korea.
}

Received January 11, 2010; accepted March 2, 2010; published online March 8, 2010

The interstitial cells of Cajal (ICCs) are pacemakers in the gastrointestinal tract. The possibility of whether imatinib mesylate, a Kit receptor tyrosine kinase inhibitor, modulates pacemaker activities in the ICC was examined using the whole cell patch clamp technique. Imatinib decreased the amplitude of pacemaker potentials in a dose-dependent manner in current-clamp mode. Because the effects of imatinib on pacemaker potentials were the same as those of pinacidil, we examined the effect of glibenclamide on ICC exposed to imatinib. The effects of imatinib on pacemaker potentials were blocked by glibenclamide. To see whether the production of prostaglandins (PGs) is involved in the inhibitory effect of imatinib on pacemaker potentials, we tested the effects of naproxen (a non-selective cyclooxygenase inhibitor) and AH6809 (a prostaglandin EP1 and EP2 receptor antagonist). Naproxen and AH6809 blocked the inhibitory effects of imatinib on ICC. Butaprost (an EP2 receptor agonist) showed the actions on pacemaker potentials in the same manner as imatinib. However, SC 19220 (an EP1 receptor antagonist) has no effects. To investigate the involvement of cAMP and protein kinase A (PKA) in the effects of imatinib on ICC, SQ 22536 (an inhibitor of adenylate cyclase) and mPKAI (an inhibitor of myristoylated PKA) were used. Both SQ-22536 and mPKAI blocked the imatinib-mediated inhibition of pacemaker potentials. However, the protein kinase C (PKC) inhibitors did not block the imatinib-mediated inhibition of pacemaker potentials. These results indicate that imatinib inhibits the pacemaker potentials of ICC by activating ATP-sensitive $\mathrm{K}^{+}$channels and PKA-dependent, PKC-independent manner.

Key words imatinib mesylate; pacemaker potential; gastrointestinal tract

Interstitial cells of Cajal (ICCs) are the pacemaking cells in the gastrointestinal (GI) muscles that generate the rhythmic oscillations in the membrane potential known as slow waves. $^{1-3)}$ Slow waves propagate within ICC networks, conduct into smooth muscle cells via gap junctions, and initiate phasic contractions by activating $\mathrm{Ca}^{2+}$ entry through L-type $\mathrm{Ca}^{2+}$ channels. The pacemaker activity in the murine small intestine is due mainly to periodic activation of nonselective cation channels (NSCCs) ${ }^{4)}$ or $\mathrm{Cl}^{-}$channels. ${ }^{5,6)}$ ICCs also mediate or transduce inputs from the enteric nervous system. Because of the central role of ICCs in GI motility, loss of these cells would be extremely detrimental. Research into the biology of ICCs provides exciting new opportunities to understand the etiology of diseases that have long eluded comprehension. ${ }^{7)}$ ICCs express the proto-oncogene $c$-kit, ${ }^{8)}$ and signalling via the receptor kinase gene product, Kit, is essential for the development of phenotype and electrical rhythmicity. ${ }^{9)}$ Although ICCs express $c$-kit receptors, it is not established whether these are functional in the adult, although they are important in developing cells. Imatinib mesylate (Glivec $^{\circledR}$; Novartis Pharmaceuticals) is a selective inhibitor of c-kit receptor tyrosine kinases, and has U.S.A. Food and Drug Administration approval for the treatment of Philadelphia chromosome-positive chronic myeloid leukaemia (CML) and c-kit positive gastrointestinal stromal tumours (GIST). ${ }^{10)}$

As both development and maintenance of ICC require Kit, ${ }^{11)}$ an inhibitor of Kit signaling could be used as a specific blocker for the function of ICC. Recently, imatinib me- sylate has been shown to suppress contractile activity in various phasic smooth muscles, including the human uterus and small intestine, ${ }^{12)}$ guinea-pig bladder, ${ }^{13)}$ guinea-pig gall bladder $^{14)}$ and guinea pig stomach. ${ }^{15)}$ However, none of the studies has demonstrated that the effects of imatinib mesylate, on pacemaker potentials in ICC. In the present study, we investigated the effects of imatinib mesylate on pacemaker potentials in ICCs in mouse small intestine.

\section{MATERIALS AND METHODS}

Preparation of Cells and Cell Cultures The mice used were treated ethically according to the Guidelines for the Care and Use of Animals approved by Pusan National University. Balb/c mice ( 8 - $13 \mathrm{~d}$ old) of either sex were anaesthetized with ether and killed by cervical dislocation. The small intestines from $1 \mathrm{~cm}$ below the pyloric ring to the caecum were removed and opened along the mesenteric border. The luminal contents were washed out with Krebs-Ringer bicarbonate solution. The tissues were pinned to the base of a Sylgard dish and the mucosa was removed by sharp dissection. Small strips of intestinal muscle (consisting of both circular and longitudinal muscles) were equilibrated in $\mathrm{Ca}^{2+}$ free Hank's solution (containing in mM: $\mathrm{KCl} 5.36, \mathrm{NaCl} 125$, $\mathrm{NaOH} 0.34, \mathrm{Na}_{2} \mathrm{HCO}_{3} 0.44$, glucose 10 , sucrose 2.9 and $N$ (2-hydroxyethyl)piperazine- $N^{\prime}$-2-ethanesulfonic acid (HEPES) 11) for $30 \mathrm{~min}$, and the cells were then dispersed with a solution containing collagenase (Worthington Biochemical Co., U.S.A.) $1.3 \mathrm{mg} / \mathrm{ml}$, bovine serum albumin (Sigma Chemical 
Co., U.S.A.) $2 \mathrm{mg} / \mathrm{ml}$, trypsin inhibitor (Sigma) $2 \mathrm{mg} / \mathrm{ml}$ and ATP $0.27 \mathrm{mg} / \mathrm{ml}$. The dispersed cells were plated onto sterile glass coverslips coated with murine collagen $(2.5 \mu \mathrm{g} / \mathrm{ml}$, Falcon/BD) in $35 \mathrm{~mm}$ culture dishes and cultured at $37^{\circ} \mathrm{C}$ in a $95 \% \mathrm{O}_{2}-5 \% \mathrm{CO}_{2}$ incubator in smooth muscle growth medium (SMGM, Clonetics Corp., U.S.A.) supplemented with $2 \%$ antibiotics/antimycotics (Gibco, U.S.A.) and murine stem cell factor (SCF, $5 \mathrm{ng} / \mathrm{ml}$, Sigma). ICCs were identified immunologically by incubation with anti-c-kit antibody [phycoerythrin (PE)-conjugated rat antimouse c-kit monoclonal antibody; eBioscience, U.S.A.] at a dilution of $1: 50$ for 20 min. ${ }^{16)}$ Since the morphology of the ICCs differed from those of other cell types in the culture, it was possible to identify them with a phase contrast microscope after incubation with anti-c-kit antibody.

Patch-Clamp Experiments The physiological salt solution used to bathe cells $\left(\mathrm{Na}^{+}\right.$-Tyrode) contained (mM): $\mathrm{KCl} 5$, $\mathrm{NaCl} 135, \mathrm{CaCl}_{2}$ 2, glucose $10, \mathrm{MgCl}_{2} 1.2$ and HEPES 10, adjusted to $\mathrm{pH} 7.4$ with $\mathrm{NaOH}$. The pipette solution contained (mм): $\mathrm{KCl} 140, \mathrm{MgCl}_{2} 5, \mathrm{~K}_{2}$ ATP 2.7, NaGTP 0.1, creatine phosphate disodium 2.5, HEPES 5 and ethylene glycol bis(2-aminoethyl ether)- $N, N, N^{\prime}, N^{\prime}$-tetraacetic acid (EGTA) 0.1 , adjusted to $\mathrm{pH} 7.2$ with $\mathrm{KOH}$. The whole-cell configuration of the patch-clamp technique was used to record membrane potentials (current clamp) of the cultured ICC, and an Axopatch I-D (Axon Instruments, U.S.A.) was used to amplify the membrane currents and potentials. Command pulses were applied using an IBM-compatible personal computer and pClamp software (version 6.1; Axon Instruments). The data were filtered at $5 \mathrm{kHz}$, displayed on an oscilloscope, computer monitor and with a pen recorder (Gould 2200, Gould, Valley View, U.S.A.), and analyzed with pClamp and Origin (version) software. All experiments were performed at $30^{\circ} \mathrm{C}$.

Drugs Butaprost and SC 19220 were purchased from cayman Chemicals (Ann Arbor, MI, U.S.A.) and 9-(tetrahydro-2-furanyl)-9H-purine-6-amine (SQ-22536) was purchased from Calbiochem Co. (San Diego, CA, U.S.A.). Glibenclamide and pinacidil were purchased from RBI (U.S.A.), and naproxen, AH6809, chelerythrine, calphostin C, guanosine $5^{\prime}$-[h-thio] diphosphate trilithium salt (GDP $\beta$ S), thapsigargin, cyclopiazonic acid, and myristoylated protein kinase A inhibitor (mPKAI) were purchased from Sigma (U.S.A.). Imatinib mesylate was kindly provided by Novartis Pharma (Basel, Switzerland). For stock solutions, all drugs were dissolved in distilled water or dimethylsulfoxide (DMSO), and stored at $-20^{\circ} \mathrm{C}$. The final concentration of DMSO in the bath solution was always $<0.1 \%$, and did not affect the recorded traces.

Statistics All data are expressed as mean \pm S.E. Student's $t$-test for unpaired data was used to compare control and experimental groups. A $p$ value of less than 0.05 was considered statistically significant.

\section{RESULTS}

Imatinib Mesylate Decreases the Amplitude of Pacemaker Potentials in Cultured ICC To understand the relationship between imatinib mesylate and modulation of pacemaker activity in ICC, we examined the effects of imatinib mesylate on pacemaker potentials in cultured ICC. In

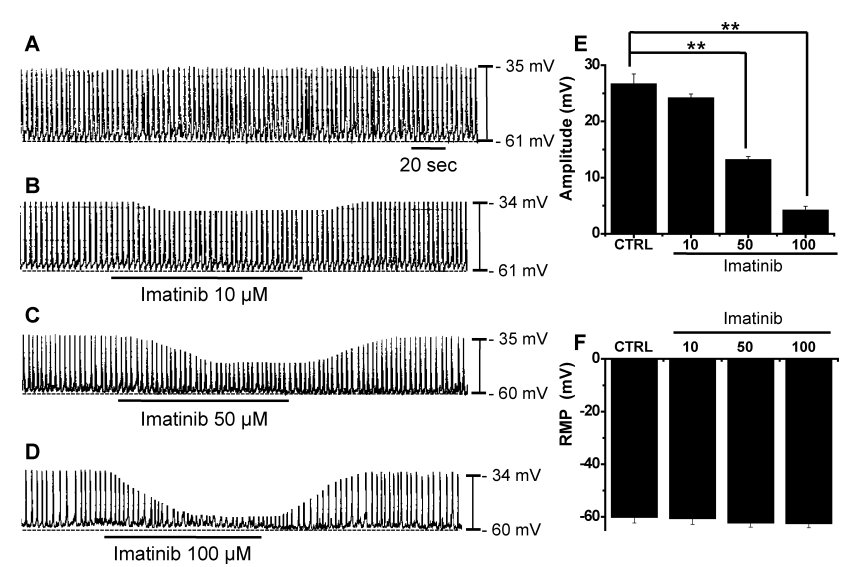

Fig. 1. Imatinib Decreases the Amplitude of Pacemaker Potentials in Cultured ICC

(A-D) In current clamp mode $(I=0)$, the addition of imatinib $(10-100 \mu \mathrm{M})$ decreases the amplitude of pacemaker potentials. (E) Bar graphic representation of the decrease of amplitude with imatinib concentration. (F) Bar graphic representation of the change of resting membrane potentials with imatinib concentration. Bars represent mean \pm S.E. $* * p<0.01)$ Significantly different from the control. CTRL: Control.

current clamp mode $(I=0)$, ICC had a mean resting membrane potential of $-60.3 \pm 1.6 \mathrm{mV}$ and produced electrical pacemaker potentials $(n=36)$. The frequency of this pacemaker potential was $19 \pm 2$ cycles/min with an amplitude of $26.8 \pm 1.7 \mathrm{mV}(n=36$; Fig. $1 \mathrm{~A})$. The addition of imatinib mesylate $(10-100 \mu \mathrm{M})$ decreased the amplitude of the pacemaker potentials, but the resting membrane potentials had little changes (Figs. 1B-D). The amplitudes were 24.25 $0.6 \mathrm{mV}$ at $10 \mu \mathrm{M}$ imatinib mesylate $(n=5), 13.31 \pm 0.5 \mathrm{mV}$ at $50 \mu \mathrm{M}(n=4), 4.35 \pm 0.7 \mathrm{mV}$ at $100 \mu \mathrm{M}(n=4)$ (Fig. 1E). The resting membrane potentials were $-61.1 \pm 0.8 \mathrm{mV}$ at $10 \mu \mathrm{M}$, $-61.8 \pm 1.2 \mathrm{mV}$ at $50 \mu \mathrm{M}$, and $-62.1 \pm 1.1 \mathrm{mV}$ at $100 \mu \mathrm{M}$ (Fig. 1F). Imatinib mesylate, however, did not have any obvious effects on their frequency (Figs. 1B-D).

Involvement of ATP-Dependent $\mathrm{K}^{+}$Channels on Pacemaker Potentials in Cultured ICC For evaluation of whether ATP-dependent $\mathrm{K}^{+}$channels are involved in the regulation of pacemaker potentials in cultured ICC, the action of pinacidil, the synthetic ATP dependent $\mathrm{K}^{+}$channel opener, was examined. In current clamp mode $(I=0)$, we examined the effect of pinacidil on the pacemaker potentials of ICC. Pinacidil produced membrane hyperpolarization and decreased the amplitude of the pacemaker potentials. In the presence of pinacidil, the membrane potential was $-63 \pm$ $1.3 \mathrm{mV}$ and the amplitude of the pacemaker potentials decreased to $4.1 \pm 0.3 \mathrm{mV}$ ( $n=5$; Fig. $2 \mathrm{~A})$. For further verification, we used glibenclamide, an ATP-sensitive $\mathrm{K}^{+}$channel blocker. This pinacidil-induced membrane hyperpolarization was blocked by the glibenclamide. Also the pretreatment of glibenclamide did not show any inhibitory effects of pinacidil on pacemaker potentials $(n=4$; Fig. $2 \mathrm{~B})$. Taken together, these findings suggest that ATP-sensitive $\mathrm{K}^{+}$channels may be involved in the regulation of pacemaker potentials in cultured ICC. After that, we examined the effect of imatinib mesylate on pacemaker potentials in the presence of glibenclamide. We confirmed that imatinib mesylate $(50 \mu \mathrm{M})$ reduced the amplitude of the pacemaker potentials. The addition of glibenclamide $(10 \mu \mathrm{M})$ reversed these effects (Figs. $2 \mathrm{C}-\mathrm{E}$ ), indicating that the inhibitory effects of imatinib mesylate on pacemaker potentials in cultured ICC are medi- 


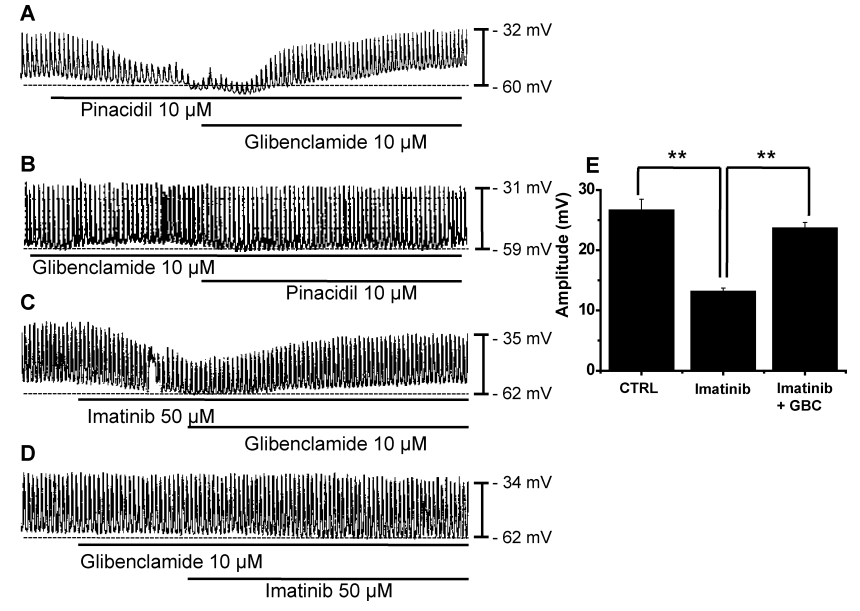

Fig. 2. Effects of Pinacidil and Imatinib on Pacemaker Potentials in Cultured ICC

(A) Pacemaker potentials of ICC exposed to pinacidil $(10 \mu \mathrm{M})$. Pinacidil decreased the frequency and amplitude of the pacemaker potentials, and these effects were reversed by adding glibenclamide $(10 \mu \mathrm{M})$. (B) The effects of pinacidil on pacemaker potentials after pretreatment with glibenclamide. (C) Pacemaker potentials were exposed to imatinib. The effects of imatinib were qualitatively the same as the effects of pinacidil on pacemaker potentials. Also, these effects were reversed adding glibenclamide. (D) The effect of imatinib on pacemaker potentials after pretreating cells with glibenclamide. (E) Bar graphic representation of the blocking response to glibenclamide on effects of imatinib. Bars represent mean \pm S.E. $* * p<0.01)$ Significantly different from the control. CTRL: Control, GBC: glibenclamide.

ated by ATP-sensitive $\mathrm{K}^{+}$channels.

Involvement of Prostaglandins Production in the Effects of Imatinib Mesylate on Pacemaker Potentials in Cultured ICC To see whether the production of prostaglandins (PGs) is involved in the inhibitory effects of imatinib mesylate on pacemaker potentials, we used naproxen, a nonselective cyclooxygenase (COX-1 and COX-2) inhibitor. Under control conditions, pretreatment with naproxen $(10 \mu \mathrm{M})$ blocked the inhibitory effect of imatinib mesylate in cultured ICC ( $n=4$; Fig. $3 \mathrm{~A})$. The average values of amplitude did not differ from control values significantly (Fig. 3B). AH6809, a prostaglandin EP1 and EP2 receptor antagonist, also completely blocked the action of imatinib mesylate on the pacemaker potentials $(n=3$; Fig. $3 \mathrm{C})$. These results indicate that the production of PGs is involved in the inhibition of pacemaker potentials in cultured ICC by imatinib mesylate.

Characterization of the EP Receptor Subtypes and Involvement of cAMP, Protein Kinase $A$ in the Effects of Imatinib Mesylate on Pacemaker Potentials in Cultured ICC To examine which the EP receptor subtypes are related to induce the inhibitory action of imatinib mesylate, first we examined the effects of butaprost, a specific agonist for the EP2 receptor subtype on pacemaker potentials. The addition of butaprost decreased the amplitude of pacemaker potentials in cultured ICC (Fig. 4A; $n=4)$. But, SC19220, an EP1 receptor antagonist, did not block the imatinib mesylatemediated inhibition of pacemaker potentials of ICC (Fig. 4B; $n=4)$. To investigate the involvement of cAMP and protein kinase A (PKA) on the effect of imatinib mesylate in pacemaker potentials, we used SQ-22536, an inhibitor of adenylate cyclase, and mPKAI, an inhibitor of myristoylated PKA. In the presence of SQ-22536 or mPKAI, imatinib mesylate had no effects on the pacemaker potentials of ICC (Figs. 4C, $\mathrm{D} ; n=4$, respectively). In the presence of SQ-22536, the rest-
A

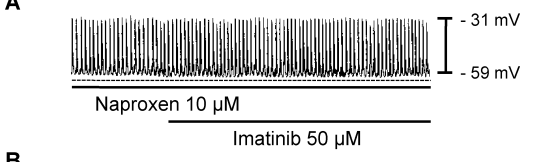

B

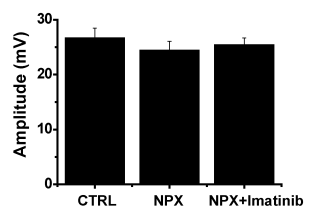

C

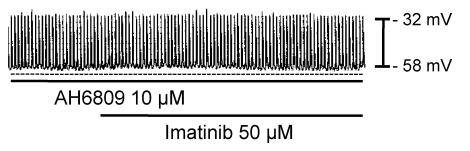

Fig. 3. Effects of Naproxen and AH6809 upon Imatinib Induced Responses of Pacemaker Potentials in Cultured ICC

(A) Naproxen $(10 \mu \mathrm{M})$ blocks the effect of imatinib on pacemaker potentials. The blocking effect of naproxen is summarized in (B). (C) Effect of AH6809 on imatinibinduced responses of pacemaker potentials. Bars represent mean \pm S.E. CTRL: Control.

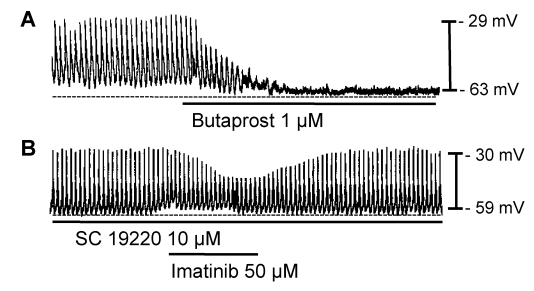

C

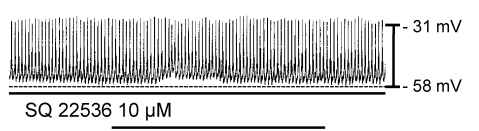

D

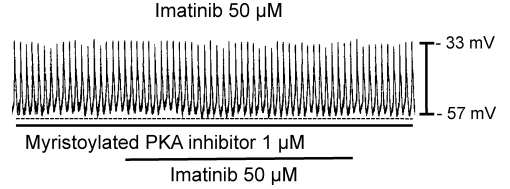

Fig. 4. Effects of EP Receptor Subtypes, Adenylate Cyclase Inhibitor and Protein Kinase A Inhibitor on Imatinib Induced Responses of Pacemaker Potentials in Cultured ICC

(A) Butaprost $(1 \mu \mathrm{M})$ decreased the amplitude of pacemaker potentials in cultured ICC. (B) SC $19220(10 \mu \mathrm{M})$ did not block the imatinib-mediated inhibition of pacemaker potentials. (C) SQ $22536(10 \mu \mathrm{M})$ blocked the imatinib-mediated inhibition of pacemaker potentials. (D) mPKAI $(1 \mu \mathrm{M})$ blocked the imatinib-mediated inhibition of pacemaker potentials.

ing membrane potentials were $58.2 \pm 1.3 \mathrm{mV}$ and the amplitude of the pacemaker potentials were $18 \pm 1$ cycles $/ \mathrm{min}$. In the presence of mPKAI, the resting membrane potentials were $57.3 \pm 1.2 \mathrm{mV}$ and the amplitude of the pacemaker potentials were $18 \pm 1 \mathrm{cycles} / \mathrm{min}$. These results suggested that imatinib mesylate inhibited the pacemaker potentials through EP2 receptor and PKA-dependent manner.

Effects of Protein Kinase $C$ Inhibitors in the Effects of Imatinib Mesylate on Pacemaker Potentials in Cultured ICC We examined the effects of chelerythrine and calphostin $\mathrm{C}$ to investigate whether imatinib mesylate induced responses of pacemaker potentials are mediated by the activation of protein kinase $\mathrm{C}(\mathrm{PKC})$. Chelerythrine $(1 \mu \mathrm{M})$ and calphostin $\mathrm{C}(10 \mu \mathrm{M})$ did not have any effect on pacemaker potentials $(n=5$; Figs. 5A, B). Pretreatment with chelerythrine and calphostin $\mathrm{C}$ did not block the imatinib mesylate induced responses (Figs. $5 \mathrm{~A}-\mathrm{C}$ ). These results indicate that $\mathrm{PKC}$ is not involved in the inhibition of pacemaker potentials in cul- 
A

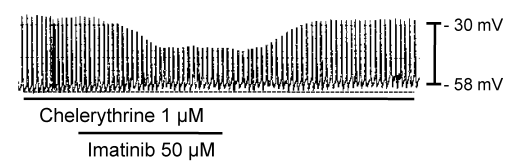

B

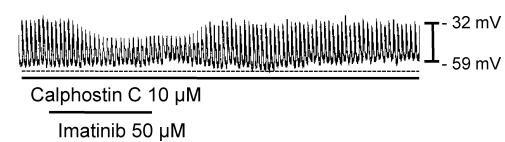

c

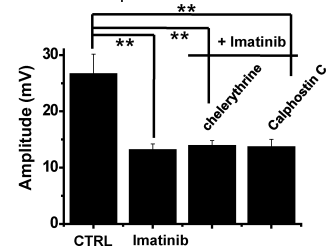

Fig. 5. Effects of Chelerythrine or Calphostin C, an Inhibitor of Protein Kinase C, on Imatinib Induced Pacemaker Potentials in Cultured ICC

(A, B) Pacemaker potentials of ICC exposed to imatinib in the presence of chelerythrine $(1 \mu \mathrm{M})$ or calphostin $\mathrm{C}(10 \mu \mathrm{M})$. Under these conditions, imatinib caused the decrease of amplitude of pacemaker potentials. Responses to imatinib in the presence of chelerythrine or calphostin $\mathrm{C}$ are summarized in $(\mathrm{C})$. Bars represent mean \pm S.E. $* * p<0.01)$ Significantly different from the control. CTRL: Control.

tured ICC by imatinib mesylate.

\section{DISCUSSION}

In this study, we found that imatinib mesylate decreased the amplitude of pacemaker activity of ICCs activating ATPsensitive $\mathrm{K}^{+}$channels via PGs dependent and PKC independent mechanism. Imatinib mesylate (STI571, Gleevec) is a tyrosine kinase inhibitor selective for Bcr-Abl expressed in Philadelphia-positive CML, activated c-kit in GIST, and platelet-derived growth factor receptor. ${ }^{17)}$ Imatinib mesylate has demonstrated very significant activity in patients with chronic phase CML as well as GIST. Imatinib was approved by the Food and Drug Administration in May 2001 for the treatment of CML that is refractory to interferon therapy and in February 2002 for the treatment of GIST. In early trials, imatinib has had extraordinary activity against CML and GIST.

The proto-oncogene $c$-kit encodes a transmembrane tyrosine kinase receptor located on the long arm of chromosome 4 (4q11.q12). Its ligand is stem-cell factor and this $c$-kit has a role in the development of normal hematopoiesis as well as in the migration of germ cells and is also expressed in normal human mast cells, immature myeloid cells, melanocytes, epithelial breast cells, and the ICCs. The immunohistochemical characteristics of the ICCs are similar to that of GIST, and GIST are considered to originate from these cells. In approximately $60 \%$ of cases of GIST, there are mutations in c-kit in the juxtamembrane domain, such as in-frame deletions ( 3 to $18 \mathrm{bp}$ ) and point mutations in exon 11. The reported rate of mutation ranges from 21 to $88 \%{ }^{18)}$ In addition to GIST, c-kit is expressed in a variety of other human cancers, including mast-cell tumors, neuroblastoma, germ-cell tumors, melanoma, small-cell lung cancer, breast and ovarian cancers, and acute myelogenous leukemia. ${ }^{19-21)}$

ICC are essential to rhythmic contractile activity, and the role of $c$-kit expression is essential for ICC morphology ${ }^{22)}$ and function: $\mathrm{W} / \mathrm{Wv}$ mice lacking $c$-kit activity have transient and random spontaneous contractile activity. ${ }^{23)}$ Tyrosine phosphorylation by protein tyrosine kinases is of particular importance in cellular signaling and can mediate signals for major cellular processes, such as proliferation, differentiation, apoptosis, attachment, and migration.

ATP-sensitive $\mathrm{K}^{+}\left(\mathrm{K}_{\text {ATP }}\right)$ channel play an important role in regulating the resting membrane potential and membrane excitability of a variety of tissues. In GI smooth muscle tissue, $\mathrm{K}^{+}$channel openers induced membrane hyperpolarization. Moreover, these effects were blocked by glibenclamide, suggesting that $\mathrm{K}_{\mathrm{ATP}}$ channel activity modulates pacemaker potentials. ${ }^{24,25)}$ In ICC, deoxycholic acid inhibited pacemaker currents by activating $\mathrm{K}_{\mathrm{ATP}}$ channels through PGE2, ${ }^{26)}$ and imipramine inhibited the activated $\mathrm{K}_{\mathrm{ATP}}$ channels. ${ }^{27)}$ Also, $K_{\text {ATP }}$ channel was involved in the response of nitric oxide or calcitonin gene-related peptide on pacemaker activity. ${ }^{28,29)}$ In this study, we have demonstrated that pinacidil inhibits pacemaker potentials, which are antagonized by glibenclamide (Fig. $2 \mathrm{~A}$ ), suggesting that $\mathrm{K}_{\mathrm{ATP}}$ channels exist in ICC, and that the activity of $\mathrm{K}_{\mathrm{ATP}}$ channels in ICC may be involved in intestinal motility. Also, imatinib produced the same effects on pacemaker potentials in ICC as pinacidil, and this imatinib-mediated inhibition of pacemaker potentials was blocked by glibenclamide (Figs. 2C, D). These result suggested that imatinib suppresses intestinal motility by the activating KATP channels in the ICC.

Intracellular $\mathrm{Ca}^{2+}\left(\left[\mathrm{Ca}^{2+}\right]_{\mathrm{i}}\right)$ oscillations in ICCs are considered to be the primary mechanism for the pacemaker activity in GI motility. ${ }^{30)}$ Nakayama et al. ${ }^{31)}$ suggested that sulphonylurea (SUR) receptors activation nearly suppressed the mechanical activity in smooth muscle, whereas ICC pacemaker $\left[\mathrm{Ca}^{2+}\right]_{\mathrm{i}}$ oscillations persisted. However, PGE2 inhibited pacemaker currents through the activation of $\mathrm{K}_{\mathrm{ATP}}$ channels and decreased intracellular $\mathrm{Ca}^{2+}$ oscillations in ICC. ${ }^{32)}$ Therefore, the exact SUR mechanism remains to be investigated. In this study, imatinib inhibited the amplitude of ICC pacemaking activity and it seems that these results may be related with intracellular $\mathrm{Ca}^{2+}$ oscillation. In future, we will perform experiment about the effects of imatinib on intracellular $\mathrm{Ca}^{2+}$ oscillation.

Several papers have shown that the PGs may be a downstream effector of imatinib. For example, imatinib was found to induce COX-2 expression and PGE2 accumulation via the epidermal growth factor receptor kinase activation in squamous carcinoma cells. ${ }^{33)}$ In addition, the involvement of COX-2 in the development of resistance to imatinib was found in K562 cells. ${ }^{34)}$ These papers were suggesting that PGE2 may serve as a downstream effector of imatinib. PGs are known to be potent regulators of the electrical and mechanical activities of GI smooth muscle. ${ }^{35,36)}$ The activity of bifunctional COX-1 and COX-2 enzymes generated PGs. COX-1 is constitutively expressed in various tissue but, COX-2 may be highly induced by cytokines and other participants in inflammatory processes. ${ }^{37,38)}$ Since ICC have seen shown to be involved in the mediation of enteric neurotransmission in GI muscles, ICC might be a site for the production of PGs within muscle layers. ${ }^{39)}$

Many reports suggested that the involvement of cAMP on PGE2 actions, especially the EP2 receptor. Hardcastle et $a l^{40)}$ suggest that positive coupling of an EP receptor to adenylate cyclase in their demonstration of an association between EP2 receptors and cAMP generation in enterocytes 
and similarly it was found an association between EP2 receptor and cAMP in corneal endothelial cells. ${ }^{41)}$ Furthermore, in cells expressing the EP2 receptor, PGE2 increased the intracellular cAMP level without any change in inositol phosphate content. ${ }^{42)}$ However, Choi et al. ${ }^{32)}$ suggested that the action of PGE2 are through EP2 receptor subtype and also the activation of ATP-dependent $\mathrm{K}^{+}$channels involves intracellular $\mathrm{Ca}^{2+}$ mobilization in ICC. In our study, on pacemaker potentials in ICC, imatinib mesylate inhibited the pacemaker potentials through EP2 receptor and cAMP, PKA dependent pathway. Namely, in ICC, the generation of pacemaker potentials and the regulation of ATP-sensitive $\mathrm{K}^{+}$ channels on this may involve the cAMP signaling. Further studies on the actions of PGE2 in ICC are needed, especially on second messenger.

Imatinib inhibited the amplitude but not frequency of ICC pacemaking activity. In various other smooth muscles, imatinib predominantly reduces the amplitude of spontaneous contractions without altering their frequency. ${ }^{12,13)}$ Recently, Hashitani et al. ${ }^{15)}$ suggested that imatinib inhibited the slow wave but not inhibited the frequency in the guinea pig corpus. Therefore, we think that this phenomenon is specific to imatinib and imatinib may not affect the initial component of pacemaker potentials. The exact mechanism remains to be investigated. Also Hashitani et al. ${ }^{15)}$ suggested that the effects of imatinib in guinea pig corpus result from inhibiting pathways that increase $\left[\mathrm{Ca}^{2+}\right]_{i}$ in smooth muscles rather than by specifically inhibiting the activity of ICC.

However, in our hands, imatinib inhibited the pacemaker potentials in cultured ICC in mouse small intestine. In this study, we used mouse model and culture system. Therefore the effects of imatinib on ICCs are required more investigation in the future.

In conclusion, imatinib inhibits the pacemaker potentials of ICC by activating ATP-sensitive $\mathrm{K}^{+}$channels via the production of PGs and PKA-dependent, PKC-independent manner.

Acknowledgement The Creative Research Initiative Center for Bio-Artificial Muscle of the Ministry of Education, Science and Technology (MEST) in Korea.

\section{REFERENCES}

1) Ward S. M., Burns A. J., Torihashi S., Sanders K. M., J. Physiol., 480, 91-97 (1994).

2) Huizinga J. D., Thuneberg L., Kluppel M., Malysz J., Mikkelsen H. B., Bernstein A., Nature (London), 373, 347-349 (1995).

3) Sanders K. M., Gastroenterology, 111, 492-515 (1996).

4) Koh S. D., Jun J. Y., Kim T. W., Sanders K. M., J. Physiol., 540, 803814 (2002).

5) Huizinga J. D., Zhu Y., Ye J., Molleman A., Gastroenterology, 123, $1627-1636$ (2002).

6) Zhu M. H., Kim T. W., Ro S., Yan W., Ward S. M., Koh S. D., Sanders K. M., J. Physiol., 587, 4905-4918 (2009).

7) Kim B. J., Lim H. H., Yang D. K., Jun J. Y., Chang I. Y., Park C. S., So I., Stanfield P. R., Kim K. W., Gastroenterology, 129, 1504-1517 (2005).

8) Maeda H., Yamagata A., Nishikawa S., Yoshinaga K., Kobayashi S., Nishi K., Nishikawa S., Development, 116, 369_753 (1992).

9) Torihashi S., Ward S. M., Nishikawa S., Nishi K., Kobayashi S.,
Sanders K. M., Cell Tissue Res., 280, 97-111 (1995).

10) Joensuu H., Roberts P. J., Sarlomo-Rikala M., Andersson L. C., Tervahartiala P., Tuveson D., Silberman S., Capdeville R., Dimitrijevic S., Druker B., Demetri G. D., N. Engl. J. Med., 344, 1052-1056 (2001).

11) Beckett E. A., Ro S., Bayguinov Y., Sanders K. M., Ward S. M., Dev. Dyn., 236, 60-72 (2007).

12) Popescu L. M., Vidulescu C., Curici A., Caravia L., Simionescu A. A., Ciontea S. M., Simion S., Eur. J. Pharmacol., 546, 177-181 (2006).

13) Kubota Y., Biers S. M., Kohri K., Brading A. F., Neurourol. Urodyn., 25, 205-210 (2006).

14) Lavoie B., Balemba O. B., Nelson M. T., Ward S. M., Mawe G. M., J. Physiol., 579, 487-501 (2007).

15) Hashitani H., Hayase M., Suzuki H., Br. J. Pharmacol., 154, 451-459 (2008).

16) Goto K., Matsuoka S., Noma A., J. Physiol., 559, 411-422 (2004).

17) Druker B. J., Talpaz M., Resta D. J, Peng B., Buchdunger E., Ford J. M., Lydon N. B., Kantarjian H., Capdeville R., Ohno-Jones S., Sawyers C. L., N. Engl. J. Med., 344, 1031-1037 (2001).

18) Miettinen M., Sarlomo-Rikala M., Lasota J., Hum. Pathol., 30, 1213 1220 (1999).

19) Krystal G. W., Honsawek S., Litz J., Buchdunger E., Clin. Cancer Res., 6, 3319-3326 (2000).

20) Arber D. A., Tamayo R., Weiss L. M., Hum. Pathol., 29, 498-504 (1998).

21) Tonary A. M., Macdonald E. A., Faught W., Senterman M. K., Vanderhyden B. C., Int. J. Cancer, 89, 242-250 (2000).

22) Torihashi S., Nishi K., Tokutomi Y., Nishi T., Ward S., Sanders K. M., Gastroenterology, 117, 140-148 (1999).

23) Shimojima N., Nakaki T., Morikawa Y., Hoshino K., Kitajima M., Pharmacology, 74, 95-99 (2005).

24) Farrway L., Huizinga J. D., J. Pharmacol. Exp. Ther, 257, 35-41 (1991).

25) Huang S. M., Nakayama S., Iino S., Tomita T., Am. J. Physiol., 275, G518-G528 (1999).

26) Jun J. Y., Choi S., Chang I. Y., Yoon C. K., Jeong H. G., Kong I. D., So I., Kim K. W., You H. J., Br. J. Pharmacol., 144, 242-251 (2005).

27) Choi S., Park C. G., Kim M. Y., Lim G. H., Kim J. H., Yeum C. H., Yoon P. J., So I., Kim K. W., Jun J. Y., Life Sci., 78, 2322-2328 (2006).

28) Park C. G., Kim Y. D., Kim M. Y., Kim J. S., Choi S., Yeum C. H., Parajuli S. P., Park J. S., Jeong H. S., So I., Kim K. W., Jun J. Y., Naunyn Schmiedebergs Arch. Pharmacol., 376, 175-184 (2007).

29) Choi S., Parajuli S. P., Yeum C. H., Park C. G., Kim M. Y., Kim Y. D., Cha K. H., Park Y. B., Park J. S., Jeong H. S., Jun J. Y., Mol. Cells, 26, $181-185$ (2008).

30) Torihashi S., Fujimoto T., Trost C., Nakayama S., J. Biol. Chem., 277, 19191-19197 (2002).

31) Nakayama S., Ohya S., Liu H. N., Watanabe T., Furuzono S., Wang J., Nishizawa Y., Aoyama M., Murase N., Matsubara T., Ito Y., Imaizumi Y., Kajioka S., J. Cell. Sci., 118, 4163-4173 (2005).

32) Choi S., Yeum C. H., Chang I. Y., You H. J., Park J. S., Jeong H. S., So I., Kim K. W., Jun J. Y., Cell. Physiol. Biochem., 18, 187-198 (2006).

33) Johnson F. M., Yang P., Newman R. A., Donato N. J., J. Exp. Ther. Oncol., 4, 317-325 (2004).

34) Arunasree K. M., Roy K. R., Anilkumar K., Aparna A., Reddy G. V., Reddanna P., Leuk. Res., 32, 855-864 (2008).

35) Sanders K. M., Northrup T. E., Am. J. Physiol., 244, G442-G448 (1983).

36) Sanders K. M., Am. J. Physiol., 247, G117-G126 (1984).

37) Herschman H. R., Cancer Metast. Rev., 13, 241-256 (1994).

38) Seibert K., Zhang Y., Leahy K., Hauser S., Masferrer J., Isakson P., Adv. Exp. Med. Biol., 400, 167-170 (1997).

39) Porcher C., Horowitz B., Bayguinov O., Ward S. M., Sanders K. M., Gastroenterolgy, 122, 1442-1454 (2002).

40) Hardcastle J., Hardcastle P. T., Redfern J. S., J. Pharm. Pharmacol., 34, 68-75 (1982).

41) Jumblatt M. M., Peterson C. A., Invest. Ophthalmol. Vis. Sci., 32 360-365 (1991).

42) Honda A., Sugimoto Y., Namba T., Watabe A., Irie A., Negishi M., Narumiya S., Ichikawa A., J. Biol. Chem., 268, 7759_7762 (1993). 